\title{
The Efficiency of Employment Relationship: Through Data Envelopment Analysis
}

\author{
Wang Kunyi ${ }^{1}$, Liu Ping, Liu Yujiang \\ Sichuan University, Chengdu, China
}

\begin{abstract}
Employment relationship (ER) is a social exchange relationship in nature with uncertainty and incongruence during the exchange process. Previous studies has been stuck on regression-based methods, examining and exploring related issue by studying the exchanges of both parties and even more stakeholders, but the nature of the exchange process itself is ignored. This study jumps out of the causality study represented by the regression analysis method, and uses the FCE that reflects the essence of object better and the Data Envelopment Analysis(DEA) to measure the efficiency of the exchange process, which can help enterprises to improve the evaluation of ER. DEA is used to evaluate the technical effectiveness of decision units (DMUs) with the same type of inputs and outputs. The result suggests that the phenomenon of inefficient exchange is still widespread. We make the importance ranking of selected inducement and find that labors in China attach importance to the correctness of management process rather than the additional benefits. For the first time, the quantitative efficiency value replaces the simple description "uncertainty" in research of the exchange process. Meanwhile, the framework independently measures the input of enterprises and the output of employees which has high adaptability. It can adjust, modify and accurately evaluate the exchange efficiency of two parties according to the actual exchange situation.
\end{abstract}

Keywords. Employment relationship, Social exchange, Data envelopment analysis, Work engagement

\section{Introduction}

ER, a social exchange relationship [1], is the most basic social relationship as one of the foundations for the development of economy. The tangible or intangible resources owned by the enterprise are exchanged with employees' performance; the company provides employees with guarantees or incentives in exchange for positive returns such as organizational commitment and high performance [2]

Regrettably, studies have shown that the exchange may not be fully efficient: the inputs of the enterprises have not been fully transformed into the expected returns from its employees [3]. The level of policy implementation of the organization may differ from the perception of employees [4], resulting in a disagreement between the two parties in most enterprises, and the employee's performance factors are not fully invested in the work [5]. The existence of this difference leads to the inefficiency of

\footnotetext{
${ }^{1}$ Corresponding Author: Wang Kunyi, Sichuan University, Chengdu, China. Email: 31788400@qq.com
} 
enterprise management, which brings unnecessary heavy burden to the normal operation of the enterprise. At the same time, enterprises are caught in the blind area of management, unable to effectively deal with various problems arising from ER management, and burying hidden dangers for the overall human resources management and strategic development. As a result, how organizations can identify better-performing projects from a wide range of alternative management tools, and improving the efficiency of ER exchange process to achieve higher levels of employee engagement and performance has become an important topic. This study introduces data envelopment analysis (DEA) to evaluate the exchange efficiency between enterprise input and employee returns in the process of ER exchange, verifies the following problems: (1) Whether the exchange process in ER is efficient; (2) Sorting the contribution of various factors invested by the enterprise to the efficiency of the exchange process and identifying inefficient inputs.

\section{Theoretical Framework and Propositions}

This model conceptualized employment relationship as an exchange relationship where employees provide contributions in exchange for inducements from organization [6][7]. The studies of perceived organizational support (POS) and leader-member exchange (LMX) hold similar view of inducements with Foa and Foa's[8] prediction. Hence, the validity of inducements through the theory of POS and LMX rely on the validity of the theory of proximity [9][10][11].

Hard inducements, or known as transactional [12][13], are measurable and tangible in employment relationships. For organization (as an anthropomorphic "employer"), the process of exchange differs from it between individuals (view the direct supervisor as "employer") and mostly its inducements are in the form of resources and management in order to build long-term trust with employee and stabilize the exchange in employment relationship. Therefore, the inducements contain HRM practices and management policies that protect employees' basic rights and economic relations (hard inducements) within the framework of labor laws. The evaluation system above can accurately and objectively reflect the employer's input level of inducements, and proposes the following propositions:

Proposition I: The hard inducements from organization can be measured by compliance in the employment relationship. Proposition II: The soft inducements from organization can be measured by competition in the employment relationship.

Work engagement (WE) is closely related with employee performance [14] and business operation [15] and it refers to the state in which organization members bring themselves into the role of work through self-management [16]. For a variety of reasons, in the process of exchange of employment relationship, the expectation of one party to the other party's obligations may be different from the other's own perception, which is called (obligation) fulfillment incongruence [17].

Proposition III: The contribution from employees can be measured by the level of their work engagement. Proposition IV: The exchange in employment relationship is inefficiency due to the incongruence in employees' and organization's perceptions of obligations. 


\section{Methodology}

In this study, 45 enterprises were selected from China, including field research and online surveys. Refer to Maas and Hox's study of the sample size requirement of cross-level models [18], removing sample enterprises that didn't archive this requirement and resulted in 38 valid enterprises with 2,711 valid surveys. Based on Liu and Duan's ER evaluation system [19], the level of inducements was measured by professional teams which contain professors and third-party HR managers through field research. The questionnaire used a seven-level short form UWES of nine items proposed by Schaufeli et al [20]. The collected data was calculated by fuzzy comprehensive evaluation (FCE) based on entropy weight method. The original DEA model was named the CCR model by the initials of Charnes [21], assuming that the scale returns were unchanged. For an DEA model which $n$ stands for the quantity of DMUs, and $m$ stands for the inputs $x_{i}$, each with a weight $v_{i}$ while $q$ stands for the outputs $y_{r}$, each with a weight $u_{r}$ The model indicates that the efficiency value of each DMU is maximized in the case where the scale return is constant and the efficiency value does not exceed 1 . The linear programming model is

$$
\begin{gathered}
\min \sum_{i=1}^{m} v_{i} x_{i k} \\
\text { s.t. } \sum_{r=1}^{s} u_{r} y_{r j}-\sum_{i=1}^{m} v_{i} x_{i j} \leq 0 \\
\sum_{r=1}^{q} u_{r} y_{r k}=1 \\
v \geq 0 ; u \geq 0 \\
i=1,2, \ldots, m ; r=1,2, \ldots, q ; j=1,2, \ldots, n
\end{gathered}
$$

The weight of all 13 input indicators including compliance and competition have been reflected in its full score. The output is calculated to one indicator thus the weight is $100 \%$. Therefore, the ER efficiency linear programming model of $D M U_{k}(k=1,2, \ldots$, 43 ) in any of the 43 companies in this study is

$$
\begin{gathered}
\min \sum_{i=1}^{11} x_{i k} \\
\text { s.t.WE }-\sum_{i=1}^{11} x_{i j} \leq 0 \\
W E_{j}=1 \\
j=1,2, \ldots, 43
\end{gathered}
$$

which $x_{i j}$ stands for the $i$ th inducements input indicator in the $j$ th sample enterprise $(k=1,2, \ldots, 43 ; i=1,2, \ldots, 11) . W E_{j}$ stands for the contribution output indicator from employees in the $j$ th sample enterprise $(j=1,2, \ldots, 43)$. 


\section{Results}

Among the valid samples, there are 5 pharmaceutical industry enterprises, 8 IT enterprises, 11 service industry enterprises, 11 manufacturing enterprises, and 3 enterprises from other industries. Among the employee data, there are $49.6 \%$ males and $50.4 \%$ are females, ranged from 15 to 60 years old. The maximum length of service is 38 years and the average is 4.8 years.

This research results in the percentile system which the highest score is 96.46 points and the lowest is 72.29 points, in average 88.25 points. For five competitive indicators results in the percentage system which the highest score is 88.64 points and the lowest is 40.00 points, in average 62.21 points.

The results are shown in Table 1.

Table 1. CFA Test for UWES-9

\begin{tabular}{|c|c|c|c|c|c|c|}
\hline & $\lambda^{2}$ & $\mathrm{df}$ & CFI & TLI & RMSEA (90\% C.I.) & SRMR \\
\hline $\begin{array}{l}\text { Single-factor } \\
\text { Model }\end{array}$ & 507.010 & 27 & 0.933 & 0.911 & $0.082(0.076,0.088)$ & 0.025 \\
\hline $\begin{array}{c}\text { Three-factor } \\
\text { Model }\end{array}$ & 461.005 & 24 & 0.939 & 0.909 & $0.083(0.077,0.090)$ & 0.025 \\
\hline
\end{tabular}

It can be seen from Table 1 that there is no significant difference in the goodness of fit indexes between the single factor model and the three factor model.

\subsection{The level of employee contribution}

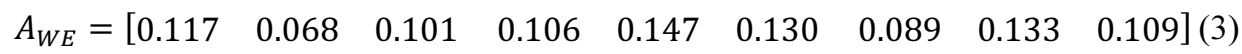

Then the discriminant matrix of each enterprise is constructed. Take a pharmaceutical industry enterprise with code A2 as an example. The enterprise has a total of 62 valid employee data, and the frequency of each item at the seven evaluation levels is shown in Table 2.

Table 2. Frequency of item choosing in A2

\begin{tabular}{lccccccc}
\hline & $\begin{array}{c}1 \\
\text { (=strongly disagree) }\end{array}$ & 2 & 3 & 4 & 5 & 6 & $\begin{array}{c}7 \\
\text { (=strongly agree) }\end{array}$ \\
\hline WE1 & 1 & 2 & 0 & 9 & 12 & 15 & 23 \\
WE2 & 1 & 2 & 0 & 4 & 6 & 18 & 31 \\
WE3 & 1 & 2 & 0 & 8 & 10 & 16 & 25 \\
WE4 & 1 & 2 & 1 & 6 & 12 & 17 & 23 \\
WE5 & 1 & 1 & 0 & 16 & 8 & 15 & 21 \\
WE6 & 1 & 1 & 0 & 11 & 13 & 16 & 20 \\
WE7 & 1 & 1 & 0 & 5 & 8 & 22 & 25 \\
WE8 & 1 & 1 & 0 & 10 & 10 & 20 & 20 \\
WE9 & 1 & 1 & 0 & 10 & 8 & 19 & 23 \\
\hline
\end{tabular}

Therefore, its evaluation matrix is (4), Using the $M(\Lambda, V)$ operator, the FCE result of $\mathrm{A} 2$ is $(5)$ 


$$
\begin{aligned}
& R_{A 2}=\left[\begin{array}{lllllll}
0.016 & 0.032 & 0.000 & 0.145 & 0.194 & 0.242 & 0.371 \\
0.016 & 0.032 & 0.000 & 0.065 & 0.097 & 0.290 & 0.500 \\
0.016 & 0.032 & 0.000 & 0.129 & 0.161 & 0.258 & 0.403 \\
0.016 & 0.032 & 0.016 & 0.097 & 0.194 & 0.274 & 0.371 \\
0.016 & 0.016 & 0.000 & 0.258 & 0.129 & 0.242 & 0.339 \\
0.016 & 0.016 & 0.000 & 0.177 & 0.210 & 0.258 & 0.323 \\
0.016 & 0.016 & 0.000 & 0.081 & 0.129 & 0.355 & 0.403 \\
0.016 & 0.016 & 0.000 & 0.161 & 0.161 & 0.323 & 0.323 \\
0.016 & 0.016 & 0.000 & 0.161 & 0.129 & 0.306 & 0.371
\end{array}\right] \\
& B_{A 2}=A_{W E} \circ R_{A 2}=\left[\begin{array}{lllllll}
0.016 & 0.032 & 0.016 & 0.147 & 0.133 & 0.147 & 0.147
\end{array}\right](5) \\
& V=\left[\begin{array}{lllllll}
1 & 2 & 3 & 4 & 5 & 6 & 7
\end{array}\right] \\
& B_{A 2}^{\prime}=\left[\begin{array}{lllllll}
0.025 & 0.050 & 0.025 & 0.230 & 0.209 & 0.230 & 0.230
\end{array}\right] \\
& W E_{A 2}=B_{A 2}^{\prime} \cdot V^{T}=5.158
\end{aligned}
$$

The FCE is used to calculate the employee work engagement scores of each researched enterprise. The full score is 7 , the highest score of the sample enterprises is 6.20 points and the lowest is 4.60 points, with an average score of 5.33 points.

\subsection{The DEA efficiency of ER}

The result is shown in Table 3 .

Table 3. DEA efficiency $\theta$

\begin{tabular}{cc|cc|cc|cc}
\hline Code $^{\mathrm{a}}$ & $\theta$ & Code & $\theta$ & Code & $\theta$ & Code & $\theta$ \\
\hline A1 & 1 & B6 & 1 & C8 & 0.96 & D7 & 0.86 \\
A2 & 0.87 & B7 & 0.97 & C9 & 1 & D8 & 0.91 \\
A3 & 1 & B8 & 0.89 & C10 & 1 & D9 & 0.86 \\
A4 & 0.92 & C1 & 1 & C11 & 1 & D10 & 0.96 \\
A5 & 1 & C2 & 1 & D1 & 1 & D1 & 0.89 \\
B1 & 1 & C3 & 0.99 & D2 & 1 & O1 & 0.99 \\
& & & & & & & \\
B2 & 1 & C4 & 1 & D3 & 0.95 & O2 & \\
& & & & & & & \\
B3 & 0.99 & C5 & 1 & D4 & 0.93 & O3 & \\
B4 & 0.96 & C6 & 1 & D5 & 0.96 & & \\
B5 & 0.95 & C7 & 0.93 & D6 & 0.96 & & \\
\hline
\end{tabular}

a: Code A stands for pharmaceutical industry, B stands for IT enterprises, C stands for service industry, D stands for manufacturing enterprises, and $\mathrm{O}$ stands for enterprises from other industries

As can be seen from Table 3, 16 enterprises have achieved DEA effective (efficiency $=1$ ), accounting for $42.11 \%$ of the total. The enterprises that does not reach DEA effective have efficiency value up to 0.99 and the lowest is 0.83 . In terms of industries, $72.73 \%$ of enterprises in service industry reached DEA efficient ER, ranking first in the four categories. Followed by pharmaceutical industry, reaching $60.00 \%$ and IT industry was $37.50 \%$. Manufacturing was the lowest. It can be seen that the exchange of ER between organizations and employees is still inefficient.

\subsection{Importance of different inducements}

In order to identify the low efficient, or invalid indicators in the inducements, this study uses the back-off method [22] to further evaluate the importance of various indicators 
in this research. In the analysis of all enterprises, the importance ranking of compliance indicators is female and juvenile protection (0.191), wages $(0.152)$, training (0.127), labor contract management $(0.071)$, social security $(0.055)$, working hours $(0.016)$. Consistent with previous studies, wages remain the most important part of hard incentives [23][24][25][26].The importance ranking of competitive indicators is democratic negotiation (0.318), labor dispute handling (0.103), employment stability (0.082), employee care (0.051), welfare system (0.035).

\section{Discussion}

The analysis results show that the phenomenon of inefficient exchange between inducements from organization and contribution from employees is widespread but with some difference. Employers should correctly treat the phenomenon of incomplete exchange and do not think about the management of ER only in terms of laws and regulations. Compared with competitive indicators, the inducing-contributing exchange process with the compliance indicators clearly limited by laws and regulations is inefficient. In terms of industries, the manufacturing industry in the four major categories showed obvious insufficient with serious ER inefficiency. According to the evaluation of specific indicators, the female and juvenile protection, wages, training, democratic negotiation and labor dispute handling are the most important indicators in the inducements. It should be noted that the DEA efficiency does not represent the absolute value.

\section{Conclusion}

Through the lens of social exchange theory, this study uses the DEA method to quantitatively evaluate the efficiency of exchange process in ER, and further ranks the importance of each inducements indicator. Compared with competitive indicators, the inducing-contributing exchange process with the compliance indicators clearly limited by laws and regulations is inefficient. In the competitive indicators, employees pay more attention to the democratic and fairness in the management process (democratic negotiation, labor disputes), followed by a sense of work safety (employment stability), which verifies the view how social comparison influence the obligation perceive in exchange relations [27]. In terms of industries, the manufacturing industry in the four major categories showed obvious insufficient with serious ER inefficiency.

According to the evaluation of specific indicators, this study believes that the female and juvenile protection, democratic negotiation have improved the sense of fairness of employees, and the wages, training, and labor disputes handling have improved the employees' sense of work safety. Both of them are important factors in social exchange research, which are in line with the conclusions of previous studies. Future research can operate further empirical tests on these points.

It should be noted that the DEA efficiency does not represent the absolute value. While paying attention to the efficiency of exchange, enterprises should not neglect the actual level of investment to balance the high quality and efficiency of ER. In addition, as a study of the exchange process, its impact on organizational performance and stability is inevitably one of the topics of continuing research. Therefore, in the future, 
variable causality research based on exchange efficiency can be further developed to more fully understand ER through the process of social exchange.

The contributions are as follows, for the first time, the quantitative efficiency value replaces the simple description "uncertainty" in research of the exchange process. Meanwhile, the framework used in this study independently measures the input of enterprises and the output of employees which has high adaptability. It can adjust, modify and accurately evaluate the exchange efficiency of two parties according to the actual exchange situation. The limitation of this study is that the research method is based on the cognitive assumption that the two groups, organization and employees, are anthropomorphized as "individuals".

\section{References}

[1] Efendiev, A., Gogoleva, A., \& Balabanova, E.. Social exchange concept as a methodological framework for employment relations analysis. Higher School of Economics Research Paper No. WP BRP, 2014, 18.

[2] Yu, M.-C., Mai, Q., Tsai, S.-B., \& Dai, Y.. An Empirical Study on the Organizational Trust, Employee-Organization Relationship and Innovative Behavior from the Integrated Perspective of Social Exchange and Organizational Sustainability. Sustainability, 2018, 10(3), 864-14.

[3] Tsui, A. S., Pearce, J. L., Porter, L. W., \& Tripoli, A. M.. Alternative approaches to the employee-organization relationship: does investment in employees pay off?. The Academy of Management Journal, 1997, 40(5), 1089-1121.

[4] Gerhart, B., Wright, P. M., Mahan, G. C. M., \& Snell, S. A.. Measurement error in research on human resources and firm performance: how much error is there and how does it influence effect size estimates?. Personnel Psychology, 2000, 53(4), 803-834.

[5] Gebauer, J., Lowman, D., \& Gordon, J.Closing the engagement gap: How great companies unlock employee potential for superior results. Penguin. 2008.

[6] Hannah, D., \& Iverson, R. Employment relationships in context: Implications for policy and practice. In Coyle-Shapiro, Jacqueline A-M., Shore, L., Taylor, M. S. and Tetrick, L. (Eds.), The employment relationship: Examining psychological and contextual perspectives: 2004,.332-350, New York, NY: Oxford University Press.

[7] Rousseau, D. M., \& McLean Parks, J.. The contracts of individuals and organizations. Research in organizational behavior, 1993,15, 1-1.

[8] Festinger, L.. (1954b). A theory of social comparison processes. Human Relations, 1954,7, 117-140.

[9] Coyle-Shapiro, Jacqueline A-M., \& Conway, N.. The employment relationship through the lens of social exchange. In Coyle-Shapiro, Jacqueline A-M., Shore, L., Taylor, M. S. and Tetrick, L. (Eds.), The employment relationship: Examining psychological and contextual perspectives: 2004, 5-28, New York, NY: Oxford University Press.

[10] Coyle-Shapiro, Jacqueline A-M., \& Conway, N.). Exchange relationships: Examining psychological contracts and perceived organizational support. Journal of applied psychology, 2005, 90(4), 774.

[11] Coyle-Shapiro, Jacqueline A-M., \& Kessler, I.. Exploring reciprocity through the lens of the psychological contract: Employee and employer perspectives. European journal of work and organizational psychology, 2002,11(1), 69-86.

[12] Robinson, S. L., \& Morrison, E. W.. Psychological contracts and OCB: The effect of unfulfilled obligations on civic virtue behavior. Journal of organizational behavior, 1995, 16(3), 289-298.

[13] Sapienza, H. J., Korsgaard, M. A., \& Schweiger, D. M.. procedural justice and changes in psychological contracts: a longitudinal study of reengineering planning. in academy of management proceedings. 1997, August,(Vol. 1997, No. 1, pp. 354-358). Briarcliff Manor, NY 10510: Academy of Management.

[14] Xi, m., liu, y.y., xu, y.f., cao, m. \& xu, z.j. A Study on Employee Engagement in Multiple Employment Relationship Modes: From the Perspective of Social Exchange Theory. Chinese Journal of Management, 2018, 15(08), 1144-1152.

[15] Schneider, B., Macey, W. H., Barbera, K. M., \& Martin, N. Driving customer satisfaction and financial success through employee engagement. People and Strategy, 2009, 32(2), 22.

[16] Kahn, W. A.. Psychological conditions of personal engagement and disengagement at work. The Academy of Management Journal, 1990, 33(4), 692-724. 
[17] Morrison, E. W., \& Robinson, S. L.. The employment relationship from two sides: Incongruence in employees' and employers' perceptions of obligations. In Coyle-Shapiro. 2004.

[18] Maas, C. J., \& Hox, J. J. Sufficient sample sizes for multilevel modeling. Methodology, 2005, 1(3), 86-92.

[19] Liu, P., \& Duan, W.P.. Research on Evaluation System of Harmonious Labor Relations: Based on Entropy Method and AHP. Innovation, Entrepreneurship and Strategy in the Era of InternetProceedings of 2016 International Conference on Strategic Management.Schaufeli, W. B., Salanova, M., González-Romá, V., \& Bakker, A. B. (2002). The measurement of engagement and burnout: A two sample confirmatory factor analytic approach. Journal of Happiness studies, 2016, 3(1), 71-92.

[20] Schneider, B., Macey, W. H., Barbera, K. M., \& Martin, N.. Driving customer satisfaction and financial success through employee engagement. People and Strategy, 2009, 32(2), 22.

[21] Charnes, A., Cooper, W. W., \& Rhodes, E.. Measuring the efficiency of decision making units. European journal of operational research, 1978, 2(6), 429-444.

[22] LOU, D. H., YI, H. G., \& YU, H.. studies of selecting variables about synthesize evaluation of perfor-mance with data envelopment analysis. Modern Preventive Medicine, 2009,9.

[23] Simon, H. A.. A formal theory of the employment relationship. Econometrica, 1951, 19(3), 293-305.

[24] Lawler, E. E., \& Lawlor, E. E.. Pay and organization development. 1981,(Vol. 268). Reading, MA: Addison-Wesley.

[25] Blau, P. Exchange and power in social life. NY: John Wiley \& Sons. 1964.

[26] Lee, C., Liu, J., Rousseau, D. M., Hui, C., \& Chen, Z. X.. Inducements, contributions, and fulfillment in new employee psychological contracts. Human Resource Management, 2011, 50(2), 201-226.

[27] Morrison, E. W., \& Robinson, S. L.. The employment relationship from two sides: Incongruence in employees' and employers' perceptions of obligations. In Coyle-Shapiro, Jacqueline A-M., Shore, L., Taylor, M. S. and Tetrick, L. (Eds.), The employment relationship: Examining psychological and contextual perspectives: 2004, 161-180, New York, NY: Oxford University Press. 